\title{
DIFFERENCES IN THE CELLULAR DISTRIBUTIONS OF TWO MICROTUBULE-ASSOCIATED PROTEINS, MAP1 AND MAP2, IN RAT BRAIN ${ }^{1}$
}

\author{
GERDA HUBER AND ANDREW MATUS ${ }^{2}$ \\ Friedrich Miescher-Institut, P. O. Box 2543, CH-4002 Basel, Switzerland
}

Received April 7, 1983; Accepted August 2, 1983

\begin{abstract}
The distribution of microtubule-associated proteins (MAPs) 1 and 2 in rat brain was studied using monoclonal antibodies. Immunochemical staining showed that both MAP1 and MAP2 are present only in neurons and both are highly concentrated in dendrites compared to axons. Otherwise, they differed in distribution in various ways. MAP1 was present at low levels in axons, whereas MAP2 was never detectable in axons with either of two different fixation methods used. In the cerebellum the two MAPs differed in relative concentration in various classes on neurons. Thus, anti-MAP1 staining was strong in Purkinje cells but very faint in granule cells, whereas anti-MAP2 staining was strong in both. There were also distributional differences within the same cell. Thus, in Purkinje cells, anti-MAP1 staining is strong in the cell body, initial axon segment and throughout the dendritic tree, but anti-MAP2 staining is present only in dendrites beyond the initial proximal portion. These results suggest that microtubules with different molecular compositions are present in the cerebellum where they are distributed differently between cells as well as within the same cell.
\end{abstract}

In addition to tubulin, brain microtubules reassembled in vitro contain a series of minor proteins which are apparently intrinsic components of the microtubule structure. Among these microtubule-associated proteins (MAPs) are two prominent high molecular weight polypeptides which have been named MAP1 and MAP2 (Sloboda et al., 1975).

MAP2 has been studied extensively. It is known to promote the assembly of tubulin into microtubules (Keates and Hall, 1975; Murphy and Borisy, 1975; Sloboda et al., $1976 \mathrm{a}, \mathrm{b}$ ), and it is phosphorylated by an intrinsic kinase activity which regulates this assemblypromoting property (Sloboda et al., 1975; Jameson et al., 1980). It is thus strongly implicated in controlling the structural state of microtubules in the cells in which it occurs. MAP1 is less well characterized, although properties such as heat lability (Fellous et al., 1977) and lack of phosphorylation (Sloboda et al., 1975) indicate that it is a species distinct from MAP2.

Recent immunohistochemical studies with polyclonal rabbit antisera have shown that some high molecular weight MAPs are selectively associated with nerve cells

\footnotetext{
${ }^{1}$ We wish to thank Gundula Pehling and Marcel Ackermann for technical and photographic assistance.

${ }^{2}$ To whom correspondence should be addressed.
}

in brain and that within these cells they are concentrated in dendrites. This suggests that these proteins play a role in dendrite-specific forms of microtubule function such as intracellular transport or the growth and maintenance of neuronal processes (Matus et al., 1981; Bernhardt and Matus, 1982).

To investigate the cellular distribution of these proteins in more detail, we have raised monoclonal antibodies against both MAP1 and MAP2. The antibodies were used to study the distributions of these molecules in brain by both immunochemical and immunocytological techniques. The results show that both are selectively associated with nerve cells and are concentrated in dendrites. In addition, their relative concentrations vary in different classes of cerebellar neurons and within different parts of the same neuron.

\section{Materials and Methods}

Preparation of subcellular fractions and antibodies. $\mathrm{Mi}$ crotubules were prepared from the brains of albino rats weighing between 160 and $180 \mathrm{gm}$ by repolymerization as described by Karr et al. (1979). In most experiments second-cycle microtubules were used as the starting preparation, with the result that microtubules tested were, in effect, third-cycle products. Higher cycle number prepa- 
rations were used in some cases, but no differences in results were detectable.

Brain intermediate filaments, synaptosomes, synaptosomal plasma membranes, and postsynaptic densities were all prepared as previously described (Matus et al., 1980). The soluble cytoplasmic fraction from synaptosomes ("synaptosol") was recovered by hypotonic lysis of synaptosomes at ice temperature and centrifugation at $100,000 \times g$ for $60 \mathrm{~min}$. Myelinated axons were prepared by a modification of the method described in Matus et al. (1980), the difference being that homogenization and centrifugation procedures were carried out in $10 \%$ $(\mathrm{w} / \mathrm{w})$ sucrose containing $8 \%(\mathrm{w} / \mathrm{v})$ Ficoll instead of the all-sucrose medium previously used. This gave better ultrastructural preservation of the cytoplasmic contents of the axon fragments. Electron microscopy showed that upward of $80 \%$ of the subcellular particles in these preparations were myelinated structures (see also Matus et al., 1980).

Preparation of antibodies. BALB/c mice were immunized with the MAP fraction from third-cycle microtubules, and clonal lines of antibody-secreting lymphocytemyeloma hybrid cells were generated using essentially the method of Galfré et al. (1977) as previously described (Hawkes et al., 1982). From a series of independently generated primary hybridomas we obtained two lines secreting antibodies whose major activity was against MAP1, and three whose major activity was against MAP2. The best secreting line from each type was subcloned at limiting dilution to confirm that the original hybridoma colonies were monoclones. Chain typing showed that both antibodies were IgG1.

Immunochemical procedures. Proteins of microtubule and other subcellular fractions were separated by SDSgel electrophoresis according to the method of Laemmli (1970), using gels containing an acrylamide concentration gradient of 4 to $15 \%$. Protein blotting onto nitrocellulose sheets (Towbin et al., 1979) and subsequent immunochemical staining (Matus et al., 1980) were performed as described, except that $0.01 \%$ SDS was added to the buffer during the electrophoretic transfer. Where various samples were to be compared, the same quantity of measured protein was loaded into adjacent channels in the same slab gel. In all cases duplicate strips were taken from the same gel blot and stained for protein with amido black (Matus et al., 1980) as a further check of comparability.

MAPs 1 and 2 were identified by their characteristic low electrophorctic migration rates, as a result of which they typically appear as two bands at the top of SDS gels (Murphy and Borisy, 1975; Sloboda et al., 1975). Their positions in our gel system are indicated on the proteinstained gel blots on the right-hand side of Figure 1. MAP2 is also identifiably by its self-catalyzed cyclic AMPstimulated incorporation of $\left[{ }^{32} \mathrm{P}\right]$ phosphate from $\left[\gamma_{-}-{ }^{32} \mathrm{P}\right]$ ATP (Sloboda et al., 1975), and we used this property as additional identification of MAP2 (B. Riederer and A. Matus, unpublished observations).

Immunohistochemistry. Immunochemical procedures were as previously described (Matus et al., 1979, 1980). Most of the tissue was fixed by transcardiac perfusion of Nembutal-anesthetized rats. The elapsed time from ces- sation of breathing to the start of perfusion was in all cases less than $45 \mathrm{sec}$ and usually less than $30 \mathrm{sec}$. The animals were perfused with isotonic saline containing heparin until the fluid issuing from the auricle was colorless and then were fixed with $200 \mathrm{ml}$ of $4 \%$ paraformaldehyde containing $0.5 \%$ glutaraldehyde in $50 \mathrm{~mm}$ phosphate buffer ( $\mathrm{pH}$ 7.4). Tissue samples were processed for electron microscopy and examined to confirm the ultrastructural preservation of microtubules and other tissue elements. Alternative fixation was performed as follows. A rat was lightly anesthetized with halothane and decapitated, and a portion of brain was dissected and immediately plunged into isopentane cooled to below $-35^{\circ} \mathrm{C}$. This procedure, from guillotine to freezing bath, took less than $30 \mathrm{sec}$. The frozen tissue was transferred to a cryostat and sections of $35 \mu \mathrm{m}$ nominal thickness were cut, picked up on cold coverslips, and immediately plunged into a cold $\left(-25^{\circ} \mathrm{C}\right)$ acetone bath inside the cryostat without being allowed to thaw. After 5 min fixation they were removed from the cryostat and air-dried. For staining they were first washed three times with buffered isotonic saline and then antibody stained using our customary immunoperoxidase procedure.

\section{Results}

The observations reported here are based on experiments with five independently generated monoclonal antibodies: two whose major activity was against MAP1, and three whose major activity was against MAP2. In addition to MAP1 itself, the anti-MAP1 antibodies faintly stained three lower bands on SDS-gel blots (Fig. 1) and, similarly, the anti-MAP2 antibodies staincd, in addition to MAP2, several other minor bands with characteristic spacings and positions on SDS gels (Fig. 1). It is well recognized that high molecular weight microtubule proteins are highly susceptible to proteolysis. MAP2 preparations are accompanied by proteolytic fragments (Sloboda et al., 1976 a, b) which have recently been reported to cross-react with monoclonal antibodies against MAP2 itself (Binder et al., 1982; Scherson et al., 1982), as they do with the monoclonal anti-MAP2 antibodies we have raised. The proteolytic origin of the minor lower bands which our monoclonal anti-MAP1 antibodies stain was indicated by experiments in which microtubules were incubated together with brain supernatant leading to a progressive increase in the proportion of lower anti-MAP1-stained bands relative to MAP1 itself (G. Huber, G. Pehling, and A. Matus, unpublished observations).

To test that the antibodies were specific for MAPs 1 and 2 , respectively, we checked their reaction with the proteins of total brain homogenate. As Figure 2 shows, each antibody reacted exclusively with its appropriate antigenic protein. We also prepared homogenates of a variety of other tissues including lung, liver, and heart and examined them to see whether antibody-reactive proteins were present. These tests were run side by side with brain homogenate samples equivalent to those shown in Figure 2, which served as a positive control. In none of the other tissues were any stained polypeptides, MAP1, MAP2, or otherwise, detectable. These results 


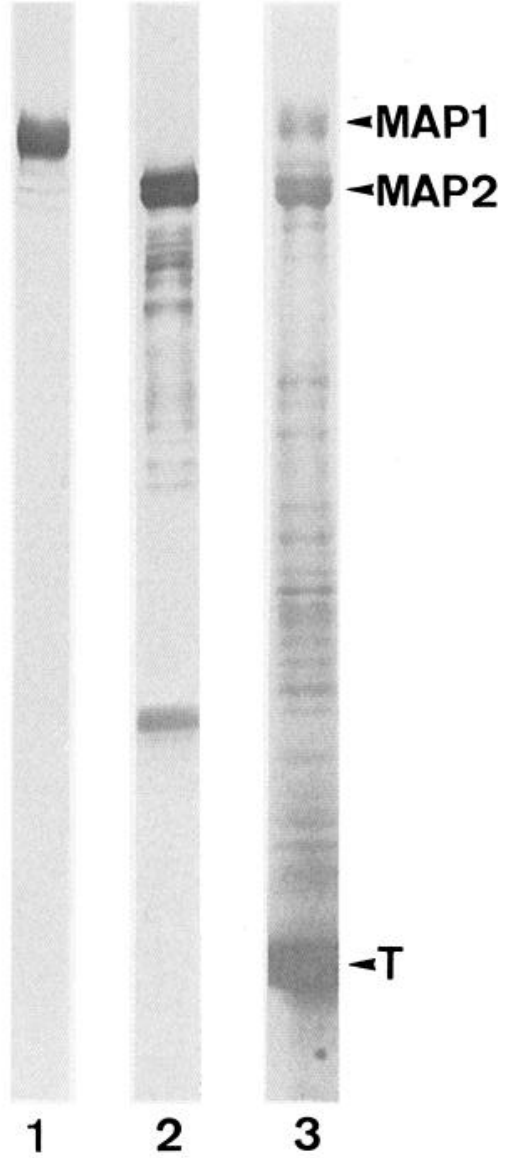

Figure 1. The specificity of monoclonal antibodies toward microtubule proteins. Samples of twice recycled microtubule proteins were separated by SDS-gel electrophoresis, then blotted onto nitrocellulose and cut into the narrow vertical strips shown. Each of the strips shown is thus an identical portion of the same original gel blot differing only in the staining they received with either anti-MAP1 (strip 1), anti-MAP2 (strip 2) or amido black for protein (strip 3). Tubulin ( $T$ ) and MAPs 1 and 2 are identified.

are in agreement with the findings of Izant and McIntosh (1980) who also used a monoclonal antibody against MAP2 to demonstrate the absence of MAP2 from nonneuronal tissues.

Immunocytochemistry. Anti-MAP1 and anti-MAP2 each stained brain sections with a characteristic and reproducible pattern. These two patterns resembled one another in one important respect: the staining was restricted to nerve cells. In the cerebellum (Figs. 3 to 5), both antibodies stained only nerve cells, although not always with the same intensity or with the same pattern (see below). Neither antibody gave detectable staining of glial or other non-neuronal cells in any of the brain areas examined.

In other respects the MAP1 and MAP2 patterns differed in ways which we now recognize as characteristic. One of the most striking of these differences was between the anti-MAP1 and anti-MAP2 staining of the interior of cerebellar Purkinje neurons. Anti-MAP1 stained both the cell body and the entire dendritic tree of these cells strongly (Figs. $3 A$ and 4). Anti-MAP2 also gave strong staining of distal Purkinje cell dendrites, but the initial

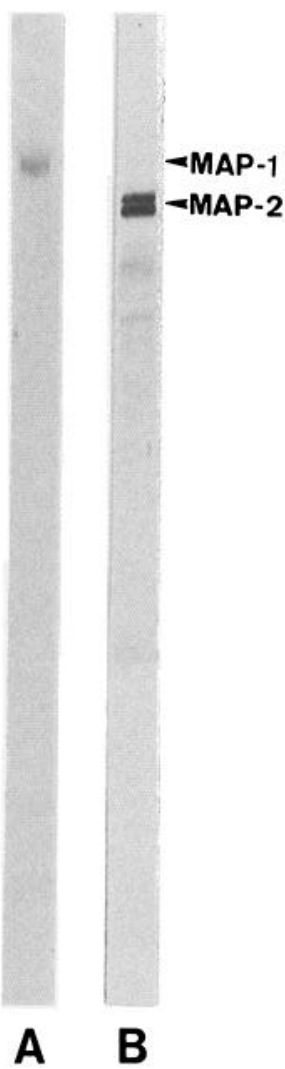

Figure 2. Staining of brain homogenate protein by antibodies against MAPs 1 and 2. Each strip was cut from the same SDSgel blot of total brain homogenate proteins. $A$ was stained with anti-MAP1 and $B$ was stained with anti-MAP2.

portion of the dendritic tree was unstained and there was no staining of the cell body (Figs. $3 B$ and 5 ).

The two antibodies also differed in their reaction with axons. MAP1 gave a faint distinct and reproducible staining of axons in white matter tracts in the cerebellum (Fig. $3 A$ ). There was also some anti-MAP1 staining of nonmyelinated axons, such as parallel fiber granule cell axons in the deeper regions of the molecular layer (Figs. $4, A$ and $B$ ). In contrast, anti-MAP2 never gave detectable staining of axons, myelinated or unmyelinated, and thus appears to be dendrite specific (Figs. $3 B$ and 5).

Even though anti-MAP1 did stain some axons, this was always much fainter than the dendritic staining by anti-MAP1 in the same cell type. For example, in Purkinje cells anti-MAP1 reacted much more intensely with the cell bodies and dendrites than with the axons of these cells in the white matter. This cannot be simply because the axons are smaller or resistant to immunostaining, because the opposite pattern, strong axonal staining and little or no dendrite reaction, was found when Purkinje cells were stained with other antisera such as anti-neurofilament protein (Matus et al., 1979) and a variety of monoclonal antibodies (Hawkes et al., 1982). In most types of neurons anti-MAP1 stained dendrites and gave no detectable reaction with axons. In the cerebellum this was the case with Golgi cells and molecular layer interneurons (Fig. 4).

Differences also existed in the intensity with which different types of neurons were stained by the two anti- 

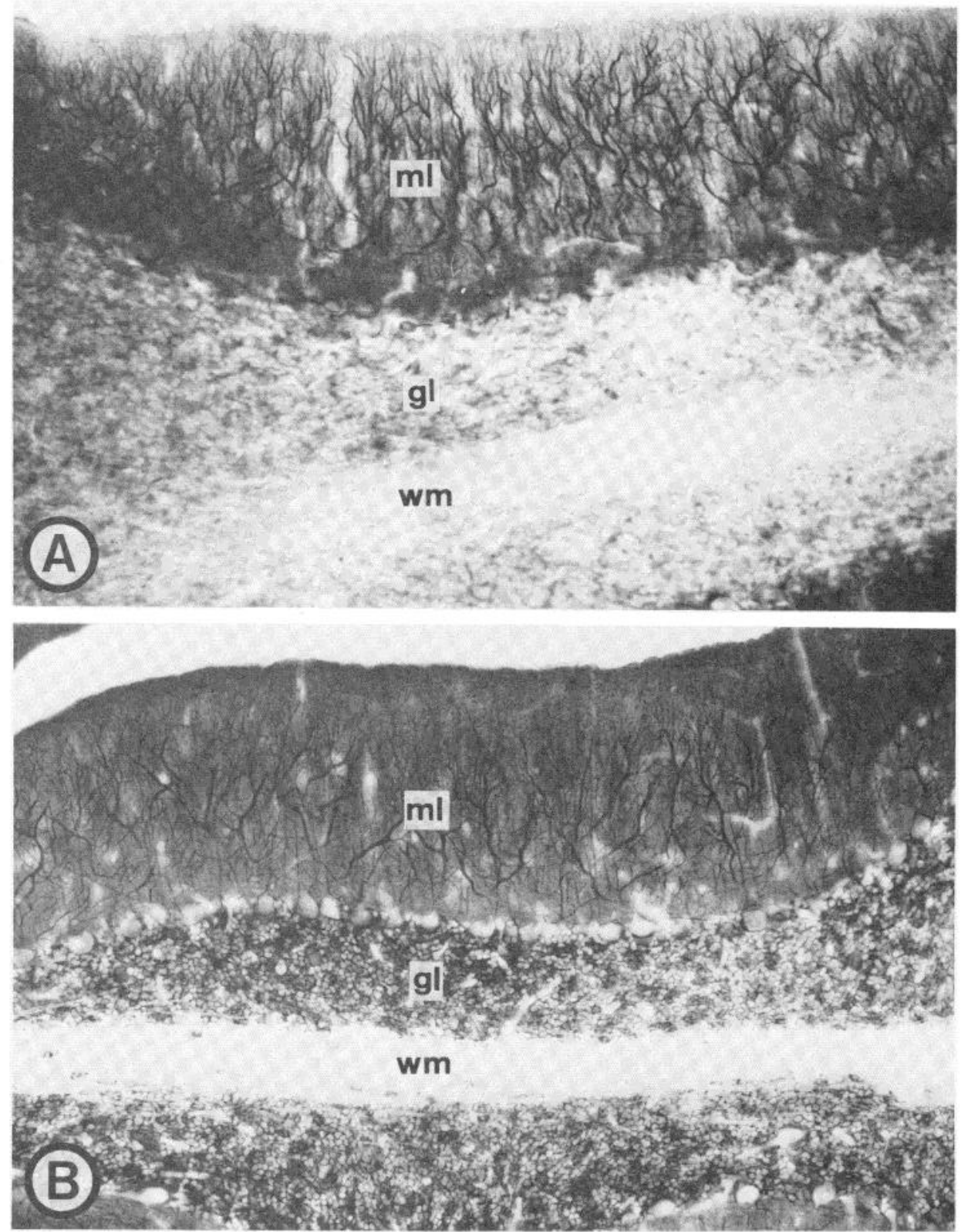

Figure 3. Immunoperoxidase staining of adjacent $40-\mu$ m-thick sections of aldehydefixed rat cerebellar cortex by $(A)$ anti-MAP1 and $(B)$ anti-MAP2. The molecular layer $(\mathrm{ml})$, granule cell layer $(\mathrm{gl})$, and white matter $(\mathrm{wm})$ are identified. Magnification $\times 100$.

bodies. Anti-MAP1 stained cell bodies and dendrites of granule cell neurons only very faintly (Fig. $3 A$, and particularly Fig. $4, A$ and $C$ ), whereas anti-MAP2 stained them very strongly (Figs. $3 B$ and $5 C$ ).

A final difference in the reactivity of the two antibodies was found in fine varicose fibers which run in a close to vertical course through the molecular layer of the cerebellum. These were stained by anti-MAP2 (Fig. $5 B$ ) but are not at all stained by anti-MAP1. Some of these are fine dendrites of basket cell interneurons and can be traced back to the cell body of their cells of origin in favorable sections. We cannot at present exclude the possibility that some of them may be monoaminergic axons, which have a similarly fine varicose appearance. However, if these varicose fibers are monoaminergic axons, then it is only the portions of them that lie in the cerebellar cortex which reacted with anti-MAP2; those portions of these same axons that lie in the deeper parts of the cerebellum and in the brainstem were not antiMAP2 stained.

Alternative fixation. The above observations are based on tissue sections taken from rats fixed with aldehyde by transcardiac perfusion at ambient temperature (Figs. 3 to 5). To check for the presence of artifacts induced by the fixative or by degradative changes during the fixation process, we examined tissue which was rapidly frozen within $30 \mathrm{sec}$ of death, then cryostat sectioned and acetone fixed without being allowed to thaw, and then stained with each of the antisera (Fig. 6). This confirmed the patterns obtained in aldehyde-perfused sections, giving even more clearly distinguishable characteristic staining. As before, the strong dendritic staining and 

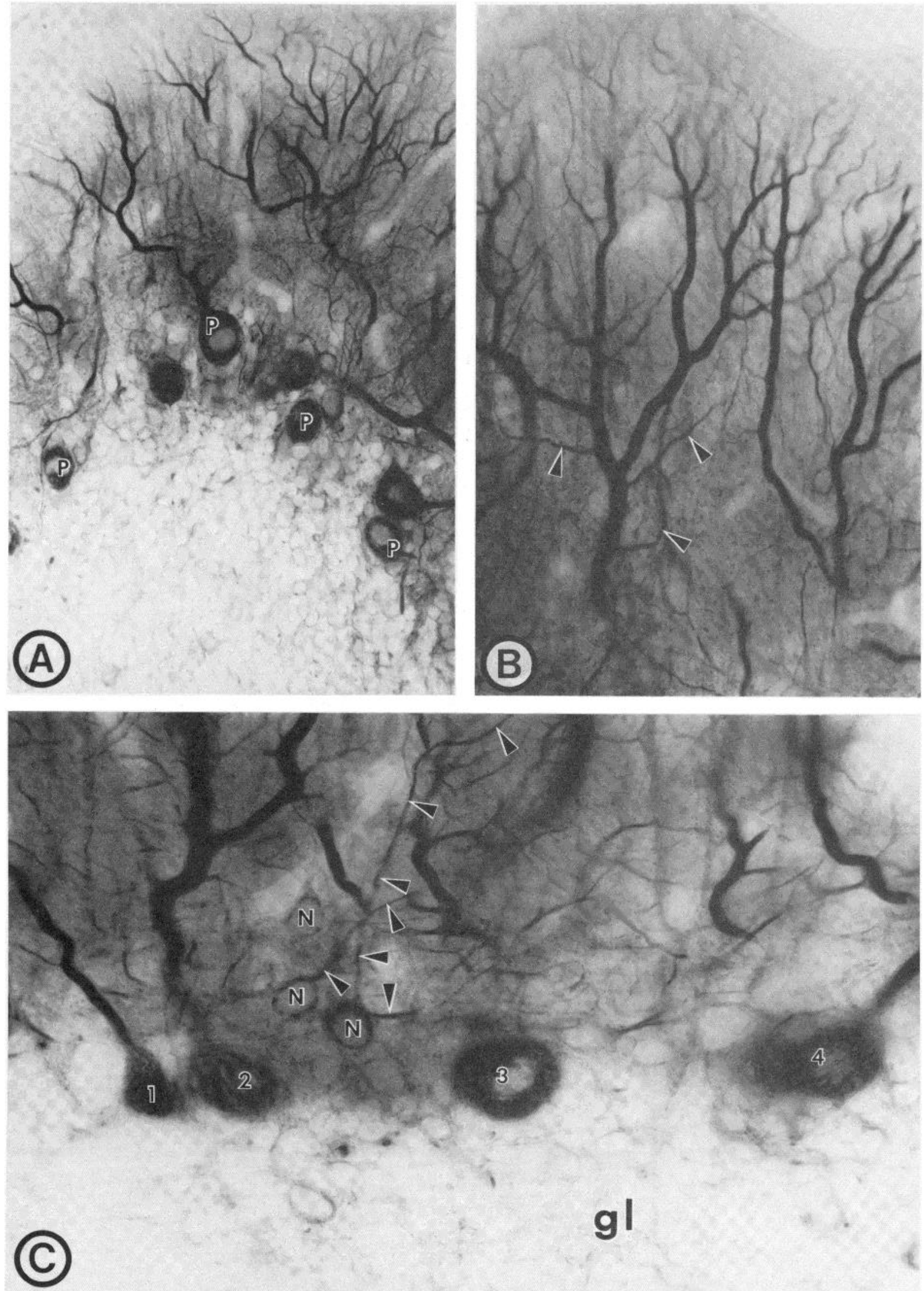

Figure 4. Staining of cerebellar cortex by anti-MAP1. The micrographs in this figure and in Figures 5 and 7 are taken from aldehyde-fixed Vibratome sections. $A$, Purkinje cell bodies $(P)$ and dendrites are strongly stained. Magnification $\times 330$. $B$, Upper section of molecular layer $\times 750$. Purkinje cell dendrites including fine terminal and collateral (arrowheads) branches are stained. $C$, Purkinje cell bodies are numbered. In cell bodies 2 and 4, fibrous bundles in the perikaryal cytoplasm are stained. The cell bodies of basket cell interneurons $(N)$ and their dendrites (arrowheads) are stained. Cells in the granular layer (gl) are only faintly reactive. Magnification $\times 600$. 

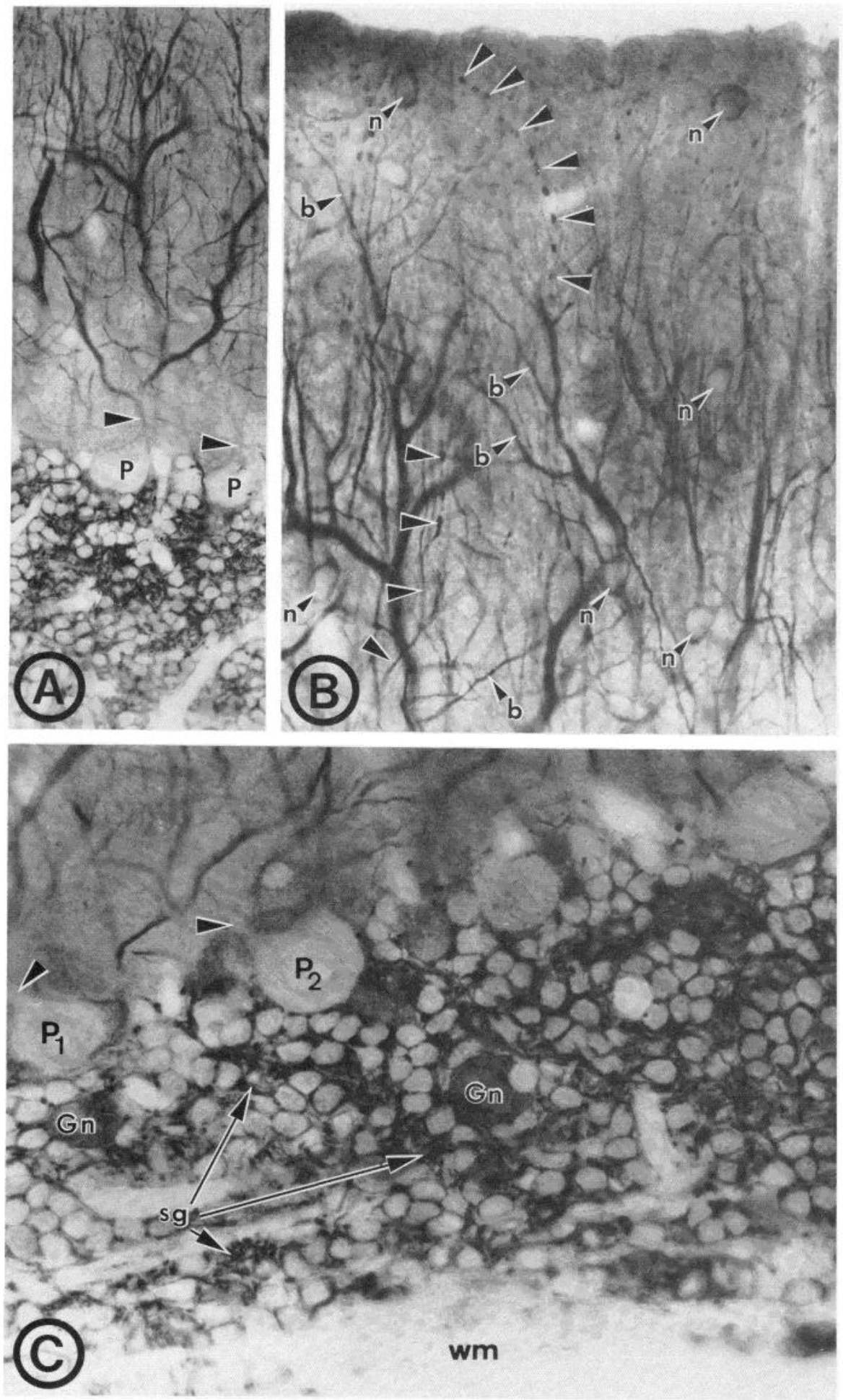

Figure 5. Rat cerebellum cortex stained with anti-MAP2. A, Purkinje cell bodies $(P)$ and proximal dendrites (arrowheads) are faintly stained compared to distal dendrites. Magnification $\times 330$. B , Upper molecular layer. Purkinje cell dendrites give rise to fine, stained terminal and collateral $(b)$ branches. Interneuron cell bodies $(n)$ and dendrites arising from them are stained. Fine caliber stained varicose fibers are indicated by arrowheads. Magnification $\times 520$. C, Purkinje cell bodies $\left(P_{1}, P_{2}\right)$ and dendrites arising from them (arrowheads) are weakly stained. The white matter axon tract $(\mathrm{wm})$ is unstained. In the granular layer granular and Gogi neuron $(G n)$ cell bodies are strongly stained as are the short dendrites of granule cells which penetrate synaptic glomeruli $(\mathrm{sg})$. Magnification $\times 700$. 

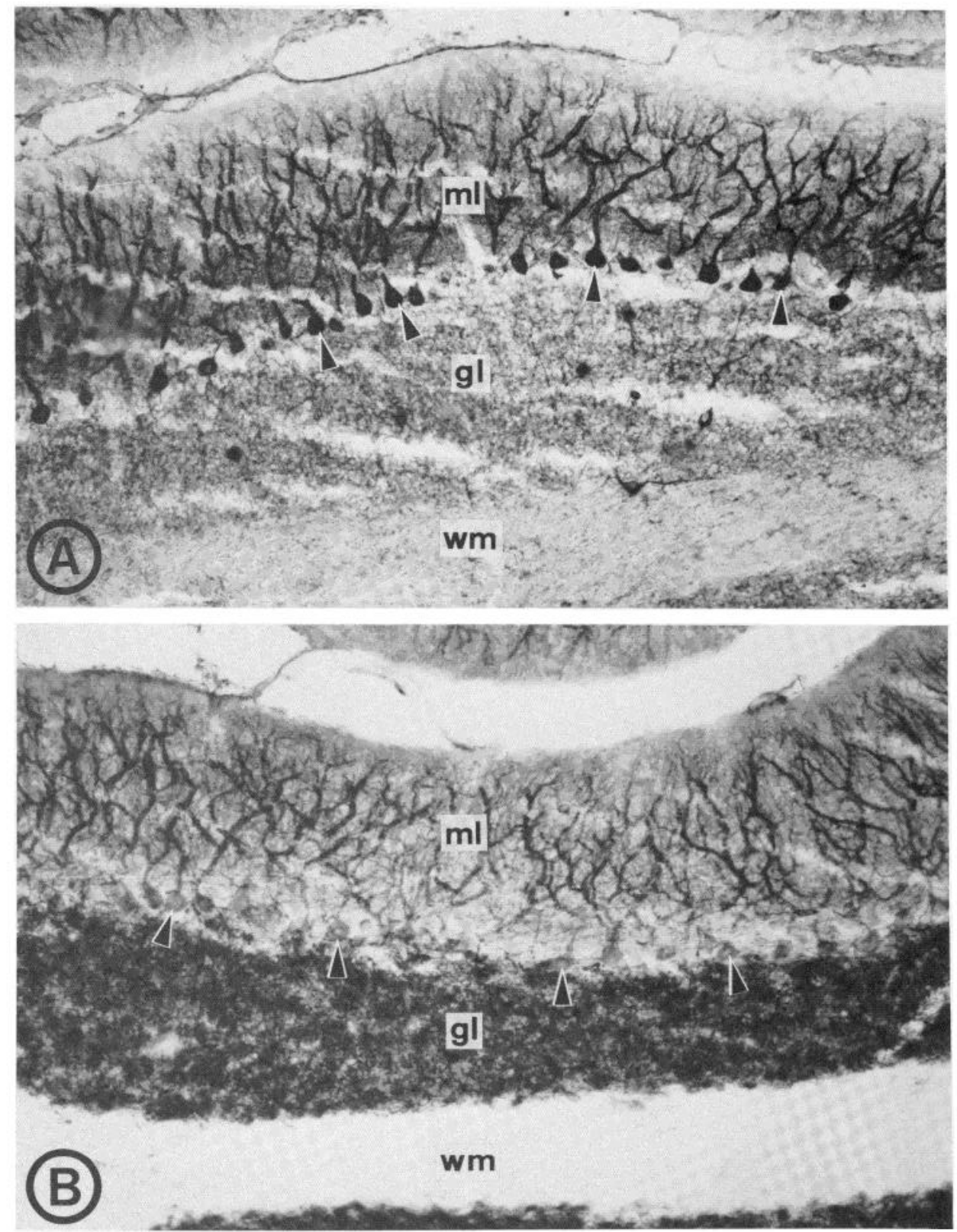

Figure 6. Staining of adjacent cryostat sections from fresh-frozen, acetone-fixed rat cerebellum with $(A)$ anti-MAP1 or $(B)$ anti-MAP2. Labeling and magnification are as in Figure 3.

absence of glial reactivity for both antisera were clearly evident. The contrasts between the MAP1 and MAP2 patterns were also clear, as comparison of Figure $6, \mathrm{~A}$ and $B$, shows. Purkinje cell bodies, strongly stained by anti-MAP1 (Fig. 6A), were at the most very faintly stained with anti-MAP2 (Fig. 6B), and white matter, faintly stained by anti-MAP1, was unstained by antiMAP2. The distinction between faint anti-MAP1 granule cell staining and the intense staining of the same cells by anti-MAP2 was particularly clear.

The major features of these staining patterns were also seen in other brain regions. In the cerebral cortex both antisera stained apical dendrites strongly and basal dendrites more weakly, with no detectable axonal or glial staining in either case (Fig. 7, upper panels). In the hippocampus (Fig. 7, lower panels) the dendrites of both granule and pyramidal cell neurons were stained whereas the intrinsic axons, commissural fibers, granule cell mossy fibers, and Schaeffer collaterals showed no apparent staining, and glial elements were also unstained.

Immunochemical tests. As further confirmation of the apparent absence of MAP1 and MAP2 from axons suggested by the immunohistochemical staining, we performed immunochemical experiments. In these we prepared brain subcellular fractions enriched in myelinated axons, separated their proteins by gel electrophoresis, and blotted them onto a single piece of nitrocellulose sheet. This was cut into several vertical strips, each containing an identical pattern of axonal proteins, and each strip was then stained with a different antibody 

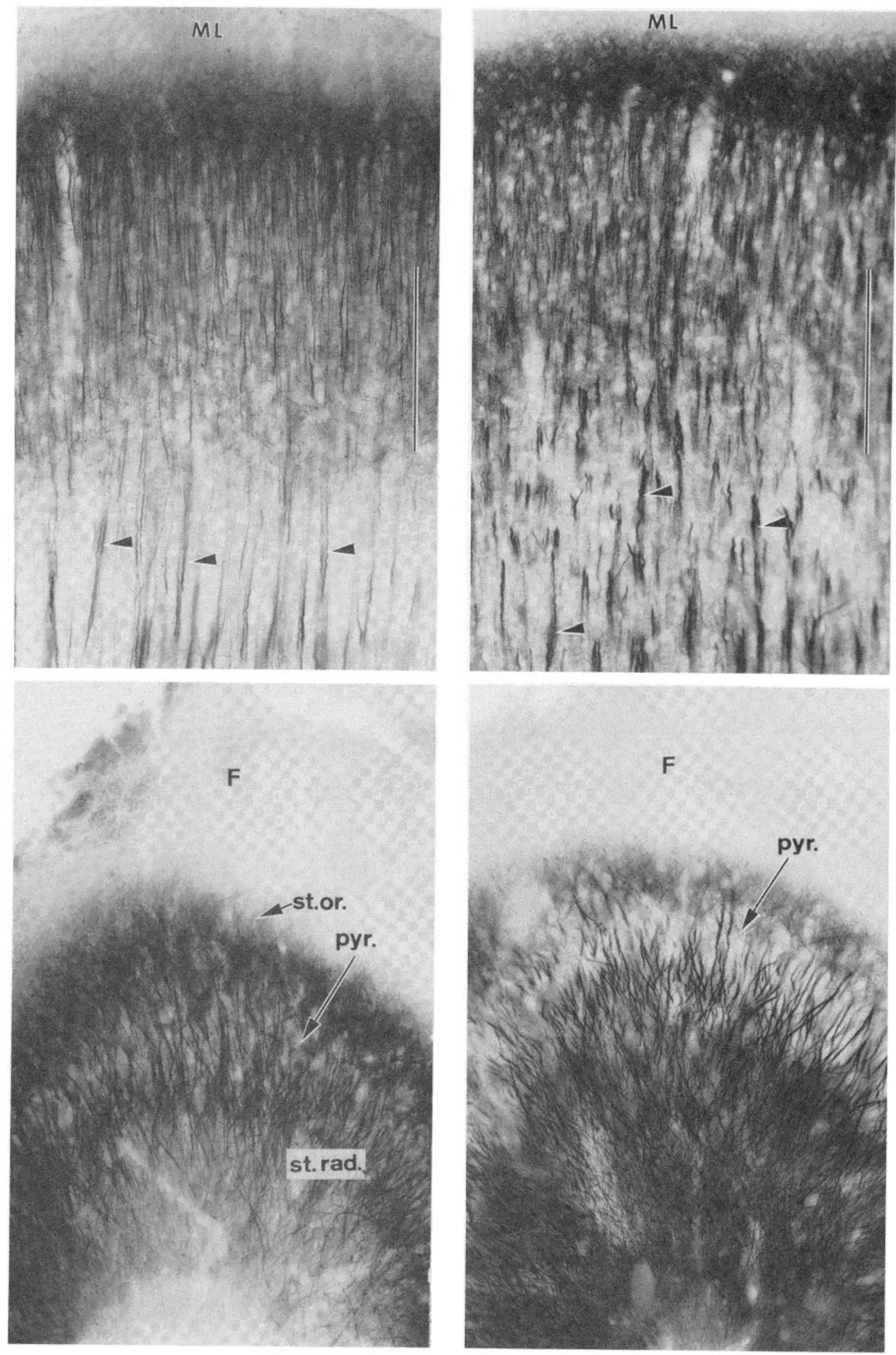
(Fig. 8). Staining with polyclonal antisera confirmed the presence of the $M_{\mathrm{r}}=68,000$ and 168,000 neurofilament peptides $A$ (Fig. $8 A$ ) and of tubulin (Fig. $8 B$ ). Two other strips were stained with either anti-MAP1 (Fig. $8 C$ ) or anti-MAP2 (Fig. $8 D$ ). There was no detectable staining in either case.

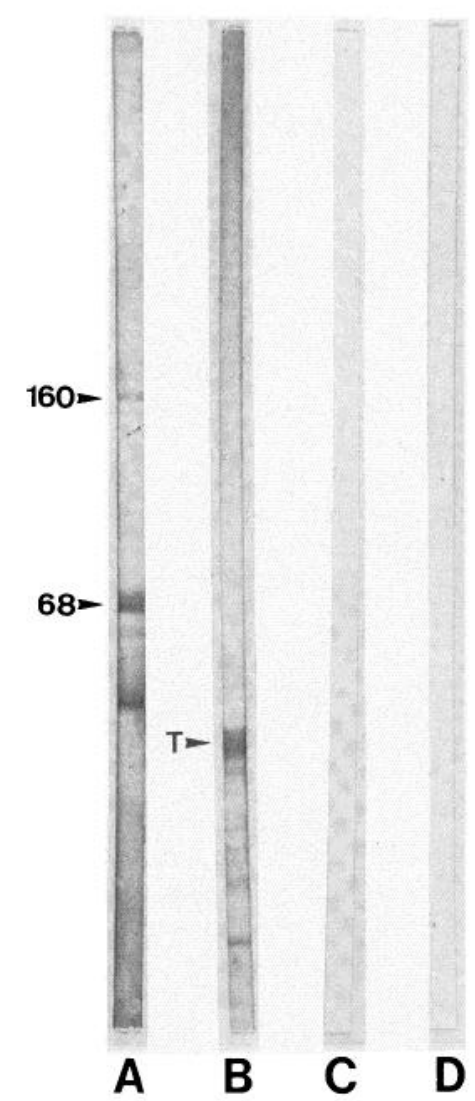

Figure 8. Immunochemical tests for the presence of MAPs 1 and 2 in myelinated brain axons. The nitrocellulose strips shown were cut from a single gel blot containing separated proteins of myelinated axons, and each stained with a different antibody: $A$, anti-neurofilament; $B$, anti-tubulin; $C$, antiMAP1; $D$, anti-MAP2.

In the immunohistochemical staining patterns it is striking that there was no apparent staining of synaptic elements by either antibody. This was true of both presynaptic terminals and of dendritic spines. The lack of antigen reactivity in the spines cannot be attributed to some general failure of the immunohistochemical method at the synapse, because we have recently been able to obtain strong and selective staining of synapses with monoclonal antibodies (Hawkes et al., 1982). As with the axons, we used immunochemical methods applied to subcellular fractions as an alternative approach to this question. Figure 9 shows blots of SDS gels containing separated proteins from brain synaptosomes (Fig. 9, strips $A$ ), the soluble contents of lysed synaptosomes ("synaptosol") (Fig. 9, strips B) or postsynaptic densities (Fig. 9, strips $C$ ). Although these strips were heavily loaded with protein (see Fig. 9, strip $P$ ), only the synaptosol showed a detectable reaction with antiMAP1(marked with an arrowhead in Fig. 9, middle, strip $B)$. Otherwise, these various elements of the synaptic structure contained very little, if any, MAP1 or MAP2.

\section{Discussion}

The most striking result to emerge from this study is the existence of differences in the tissue distributions of MAP1 and MAP2 as shown by our monoclonal antibodies. There are intercellular differences, the most obvious being between the strong reaction of anti-MAP2 with cerebellar granule cell neurons and the weak reaction of anti-MAP1 with the same cells. There are also distributional differences within the same cell, the most striking of these being in Purkinje neurons where anti-MAP1 reacts with cell body, initial segments of axon, and all of the dendritic tree, but anti-MAP2 reacts selectively with the dendrites distal to the initial dendrite segment. These differences were found repeatedly in adjacent sections from the same tissue block. They also occurred in both aldehyde-perfused and rapidly frozen, acetone-fixed tissue. Since both antibodies are monoclonal IgG1s and the stainings were performed simultaneously using (aside from the antibody) the same reagents, it seems unlikely that the differences are preparative artifacts; they prob-

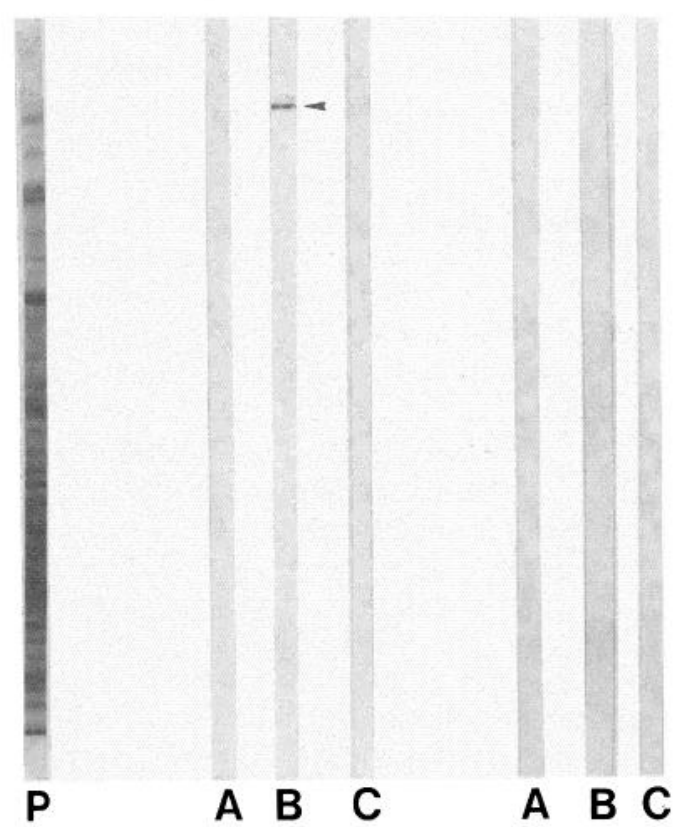

Figure 9. Immunochemical test for the presence of MAPs 1 and 2 in subcellular fractions enriched in components of brain synapses. The strip labeled $P$ contains synaptosome proteins stained with amido black. The two other sets contain proteins of synaptosomes $(A)$, synaptosol $(B)$, and postsynaptic densities $(C)$. The middle set stained with anti-MAP1, the set on the right stained with anti-MAP2.

Figure 7. Staining of cerebral cortex (upper panels) and CA3 region of the hippocampus (lower panels) by anti-MAP1 (left) and anti-MAP2 (right). ML, molecular layer of cerebral cortex; $F$, fimbria; st.or., stratum oriens; pyr., pyramidal cell body layer; st. rad., stratum radiatum. Arrowheads indicate typical apical dendrite bundles of cortical pyramidal cells in the upper panels. Magnification $\times 250$. 
ably represent genuine differences in the inter- and intracellular distributions of MAP1 and MAP2.

Since both MAP1 and MAP2 are microtubular proteins, as has been confirmed in this study using the monoclonal antibodies, the differences between their tissue distributions indicate further the presence of microtubule heterogeneity in brain which we have already described (Matus et al., 1981). The results suggest the existence of separate classes of brian microtubules ( $i$ ) containing neither MAP1 nor MAP2 (e.g., in most axons and all non-neuronal cells), (ii) containing MAP1 but not MAP2 (in some axons and Purkinje cell bodies), and (iii) which either contain both MAP1 and MAP2 or contain only MAP2. This last category is complicated since, in the dendrites of most cells (e.g., Purkinje cells and neocortical and hippocampal pyramidal cells), MAP2 staining is always overlapped by MAP1 staining. In the strongly anti-MAP2-stained cell bodies and dendrites of cerebellar granule neurons there is also weak anti-MAP1 staining. This could mean that there are separate MAP1- and MAP2-containing microtubules at these sites which differ in relative number, or that the ratio of MAP1 to MAP2 in each microtubule is higher in Purkinje cell dendrites than in granule cells.

The extremely low levels of MAP2 in Purkinje cell bodies and initial dendrite segments is particularly intriguing. It suggests that most MAP2-containing microtubules start in dendrites, where there are no visible microtubule-organizing centers. In this respect our observations support and extend the results of Chalfie and Thomson (1979), which suggested that microtubules in neuronal processes (axons in that case) can make a proximal start without the aid of an independent initiating structure. An alternative possibility is that dendritic microtubules vary in composition along their length, containing MAP2 only in their distal portions. It is also worth noting that, in contrast to the mature Purkinje cells discussed here, the cell bodies of developing Purkinje cells in neonatal brain stain strongly with antiMAP2 (Bernhardt and Matus, 1982).

Based on the known functions of microtubules in mediating intracellular transport and supporting the growth and maintenance of neuronal processes, we have previously suggested that dendritic MAPs may be part of a molecular mechanism for marking out a dendritic export route from the cell body or may be involved in dendritic development (Matus et al., 1981). There is some evidence from immunohistochemical studies for this second proposal in the case of MAP2 (Bernhardt and Matus, 1982). The question now arises whether both MAP1 and MAP2 microtubules are involved in microtubule-mediated transport or in dendrite growth and maintenance.

\section{References}

Bernhardt, R., and $\Lambda$. Matus (1982) Initial phase of dendrite growth. J. Cell Biol. 92: 589-593.

Binder, L. I., M. R. Payne, H. Kim, V. R. Sheridan, D. K. Schroeder, C. C. Walker, and L. I. Rebhun (1982) Production and analysis of monoclonal hybridoma antibodies specific for $\beta$-tubulin and MAP2. J. Cell Biol. 95: 349a.

Chalfie, M., and J. N. Thomson (1979) Organization of neuronal microtubules in the nematode Caenorhabdilis elegans. J. Cell Biol. 82: 278-289.

Fellous, A., J. Francon, A. -M. Lennon, and J. Nunez (1977) Microtubule assembly in vitro. Eur. J. Biochem. 78: 167-174.

Galfré, G., S. Howe, C. Milstein, G. W. Butcher, and J. C. Howard (1977) Antibodies to major histocompatibility antigens produced by hybrid cell lines. Nature 266: 550-552.

Hawkes, R., E. Niday, and A. Matus (1982) Monoclonal antibodies reveal novel neural antigens. Proc. Natl. Acad. Sci. U. S. A. 79: 2401-2414.

Izant, J. G., and J. R. McIntosh (1980) Microtubule-associated proteins: A monoclonal antibody to MAP2 binds to differentiated neurons. Proc. Natl. Acad. Sci. U. S. A. 77: 47414745 .

Jameson, L., T. Frey, B. Zeeberg, F. Daldorf, and M. Caplow (1980) Inhibition of microtubule assembly by phosphorylation of microtubule-associated proteins. Biochemistry 19 : $2472-2479$

Karr, T. L., H. D. White, and D. L. Purich (1979) Characterization of brain microtubule proteins prepared by selective removal of mitochondrial and synaptosomal components. J. Biol. Chem. 254: 6107-6111.

Keates, R. A. B., and R. H. Hall (1975) Tubulin requires an accessory protein for self-assembly into microtubules. Nature 257: 418-421.

Laemmli, U. K. (1970) Cleavage of structural proteins during the assembly of the head bacteriophage T4. Nature 227: 680685.

Matus, A., M. L. Ng, and D. H. Jones (1979) Immunohistochemical localization of neurofilament antigen in rat cerebellum. J. Neurocytol. 8: 513-525.

Matus, A., G. Pehling, M. Ackermann, and J. Maeder (1980) Brain postsynaptic densities: Their relationship to glial and neuronal filaments. J. Cell Biol. 87: 346-359.

Matus, A., R. Bernhardt, and T. Hugh-Jones (1981) HMWP proteins are preferentially associated with dendritic microtubules in brain. Proc. Natl. Acad. Sci. U. S. A. 78: 30103014.

Murphy, D. B., and G. G. Borisy (1975) Association of highmolecular weight proteins with microtubules and their role in microtubule assembly in vitro. Proc. Natl. Acad. Sci. U. S. A. 72: 2696-2700.

Scherson, T., B. Geiger, Z. Eshhar, and U. Z. Littauer (1982) Mapping of distinct structural domains on microtubule-associated protein 2 by monoclonal antibodies. Eur. J. Cell Biol. 129: 295-302.

Sloboda, R. D., S. A. Rudolph, J. L. Rosenbaum, and P. Greengard (1975) Cyclic AMP-dependent endogenous phosphorylation of a microtubule-associated protein. Proc. Natl. Acad. Sci. U. S. A. 72: 177-181.

Sloboda, R. D., W. L. Dentler, R. A. Bloodgood, B. R. Telzer, S. Granett, and J. L. Rosenbaum (1976a) Microtubule-associated proteins (MAPs) and the assembly of microtubules in vitro. Cold Spring Harbor Conf. Cell Proliferation 3: 1171 121.

Sloboda, R. D., W. L. Dentler, and J. L. Rosenbaum (1976b) Microtubule-associated proteins and stimulation of tubulin assembly in vitro. Biochemistry 15: 4497-4505.

Towbin, H., T. Stachelin, and J. Gordon (1979) A procedure for the electrophoretic transfer of proteins from polyacrylamide gels to nitrocellulose sheets and some applications. Proc. Natl. Acad. Sci. U. S. A. 76: 4350-4354. 